\title{
Oliceridine is Associated with Reduced Risk of Vomiting and Need for Rescue Antiemetics Compared to Morphine: Exploratory Analysis from Two Phase 3 Randomized Placebo and Active Controlled Trials
}

\author{
Timothy L. Beard · Cathy Michalsky · Keith A. Candiotti • \\ Paul Rider • Linda Wase · Ashraf S. Habib • Mark A. Demitrack • \\ Michael J. Fossler · Eugene R. Viscusi
}

Received: September 23, 2020 / Accepted: October 28, 2020 / Published online: November 18, 2020

(C) The Author(s) 2020, corrected publication 2021

\begin{abstract}
Introduction: Use of parenteral opioids is a major risk factor for postoperative nausea and vomiting. Conventional opioids bind to $\mu$-opioid
\end{abstract}

Electronic Supplementary Material The online version of this article (https://doi.org/10.1007/s40122020-00216-X) contains supplementary material, which is available to authorized users.

T. L. Beard $(\bowtie)$

Department of Surgery and Clinical Research, Summit Medical Group, Bend Memorial Clinic, Bend, OR, USA

e-mail: tbeard@bendbroadband.com

C. Michalsky · L. Wase · M. A. Demitrack .

M. J. Fossler

Trevena, Inc., Chesterbrook, PA, USA

K. A. Candiotti

Department of Anesthesiology, Perioperative Medicine, and Pain Management, University of

Miami, Miller School of Medicine, Miami, FL, USA

P. Rider

Department of Surgery, University of South

Alabama Medical Center, Mobile, AL, USA

\section{A. S. Habib}

Department of Anesthesiology, Duke University

Medical Center, Durham, NC, USA

E. R. Viscusi

Department of Anesthesiology, Sidney Kimmel

Medical College, Thomas Jefferson University,

Philadelphia, PA, USA receptors (MOR), stimulate both the G-protein signaling (achieving analgesia); and the $\beta$-arrestin pathway (associated with opioid-related adverse effects). Oliceridine, a next-generation IV opioid, is a G-protein selective MOR agonist, with limited recruitment of $\beta$-arrestin. In two randomized, placebo- and morphine-controlled phase 3 studies of patients with moderate-to-severe acute pain following bunionectomy or abdominoplasty, oliceridine at demand doses of $0.1,0.35$, and $0.5 \mathrm{mg}$ provided rapid and sustained analgesia vs. placebo with favorable gastrointestinal (GI) tolerability. In this exploratory analysis, we utilized a clinical endpoint assessing gastrointestinal tolerability, "complete GI response" defined as the proportion of patients with no vomiting and no use of rescue antiemetic to characterize the GI tolerability profile of oliceridine vs. morphine.

Methods: A logistic regression model was utilized to compare oliceridine (pooled regimens) vs. morphine, after controlling for analgesia (using the sum of pain intensity difference [SPID]-48/24 [bunionectomy/abdominoplasty] with pre-rescue scores carried forward for $6 \mathrm{~h}$ ). This analysis excluded patients receiving placebo and was performed for each study separately and for pooled data from both studies.

Results: In the unadjusted analysis, a significantly greater proportion of patients in the placebo (76.4\%), oliceridine $0.1 \mathrm{mg}(68.0 \%)$, and $0.35 \mathrm{mg}$ (46.2\%) demand dose achieved complete GI 
response vs. morphine $1 \mathrm{mg}(30.8 \%), p \leq 0.005$. In the adjusted analysis, after controlling for analgesia, the odds ratio of experiencing a complete GI response with oliceridine (pooled regimens) vs. morphine was 3.14 (95\% CI: 1.78, 5.56; $p<0.0001)$ in bunionectomy study and 1.92 (95\% CI: $1.09,3.36 ; p=0.024)$ in abdominoplasty study. Conclusions: When controlled for the analgesic effects (constant SPID-48/24), the odds ratio for complete GI response was higher with oliceridine than morphine, suggesting better GI tolerability with oliceridine.

Keywords: Opioid analgesic; Opioid-induced adverse events; Postoperative; Vomiting

\section{Key Summary Points}

Why carry out this study?

Postoperative nausea and vomiting (PONV) are frequent complications following surgery and use of conventional opioids increases risk of PONV.

Oliceridine, a new class of IV opioid, is a G protein-selective agonist at the $\mu$-opioid receptor. This selectivity results in potent analgesia with substantially reduced recruitment of $\beta$-arrestin, a signaling pathway associated with opioid-related adverse events.

In two randomized, placebo- and activecontrolled phase 3 studies, we have previously reported that oliceridine administered via PCA provided effective analgesia with improvements in gastrointestinal (GI) tolerability profile compared to morphine.

To further characterize the GI tolerability profile of oliceridine vs. morphine after controlling for analgesia, we performed an exploratory analysis that utilized a composite endpoint, "complete GI response" defined as the proportion of patients with no vomiting and no use of rescue antiemetic. This analysis was conducted for the individual studies and the pooled data from both studies.

\section{What was learned from the study?}

In the unadjusted analysis, oliceridine had a favorable advantage compared to morphine related to the safety endpoint of "complete GI response".

The findings persisted when adjusted for the level of analgesia, with the odds of achieving complete GI response being 2-3 times higher with oliceridine than with morphine.

\section{DIGITAL FEATURES}

This article is published with digital features, including a summary slide and video, to facilitate understanding of the article. To view digital features for this article go to https://doi.org/10. 6084/m9.figshare. 13150850 .

\section{INTRODUCTION}

Postoperative nausea and vomiting (PONV) are frequent complications following surgery, with a reported 30\% incidence among all post-surgical patients and up to $80 \%$ incidence among high-risk patients [1]. Some well-known risk factors for increased PONV are female gender, age $<50$ years, non-smoking status or a history of PONV, or motion sickness [1, 2]. The clinical and economic consequences of PONV are significant, with adverse consequences ranging from a decreased sense of well-being and dehydration to extreme consequences such as electrolyte imbalances, pulmonary aspiration, or wound dehiscence, resulting in delayed recovery, unexpected hospital admission, and delayed return to work [3-5]. These consequences are associated with increased healthcare costs resulting from extended recovery room stays and delay to discharge $[3,6]$.

There are several established clinical factors that are known to be associated with increased risk of PONV $[1,4]$. In addition to the patientrelated factors identified for high risk as stated above, conditions such as abdominal 
pathology, pregnancy, increased intracranial tension, or full stomach have also been reported to increase the risk of PONV. Procedures such as laparoscopies, gynecological and longer-duration surgeries are also known to be associated with an increased incidence of PONV. Likewise, the use of general anesthesia and postoperative use of opioids are known to increase the incidence $[1,4]$ of this complication. Predictive scoring systems, which include several of these factors, have been developed to identify patients at risk for PONV. For example, the Apfel score has been used widely as a validated scoring system [7].

Conventional opioids, regardless of administration route, are well known to increase the risk for PONV in a dose-dependent manner $[4,8]$. Although the precise mechanism underlying opioid-induced nausea and vomiting is incompletely understood, multiple mechanisms are likely involved [9]. A predominant mechanism involves opioid-induced activation of the $\mu$-opioid receptor (MOR) in the chemoreceptor trigger zone, as well as the activation of the opioid receptors $\mu$-, $\kappa-$, and $\delta$-subtype in the gastrointestinal (GI) tract, resulting in reduced peristalsis and delayed gastric emptying $[9,10]$. At the cellular level, conventional opioid agonists bind to MOR and stimulate $G$ protein postreceptor signaling leading to analgesia, and activation of the $\beta$-arrestin pathway leading to unwanted effects including respiratory and GI related effects [11]. In preclinical studies, $\beta$-arrestin-2 knockout mice receiving morphine have demonstrated enhanced analgesic effects with less respiratory depression and GI dysfunction compared with morphine-treated wild-type animals [12, 13]. Therefore, opioids that selectively confer preferential activation through the $G$ protein signaling pathway over the $\beta$-arrestin pathway, or that provide functional selectivity of the $G$ protein signaling pathway offer the potential for full analgesic effects while reducing the risk of adverse events $[14,15]$. Oliceridine, a next-generation intravenous (IV) opioid recently approved for clinical use, is a G-protein selective agonist at the MOR, with limited recruitment of $\beta$-arrestin $[16,17]$.
In two randomized, double-blind, placeboand morphine-controlled phase 3 pivotal studies in patients with moderate-to-severe acute pain following either orthopedic surgerybunionectomy (Apollo-1), or plastic surgeryabdominoplasty (Apollo-2), oliceridine at demand doses of $0.1,0.35$, and $0.5 \mathrm{mg}$ provided rapid and effective analgesia compared to placebo with a favorable safety profile $[18,19]$. In both trials, patients enrolled had Apfel risk scores $\geq 3$ prior to randomization, indicating they were at increased risk for the development of PONV. Neither protocol permitted the use of prophylactic antiemetics in order to provide a clearer determination of the gastrointestinal (GI) tolerability profile of the treatments in the studies. Across the two studies, the incidence of nausea was lower with oliceridine $0.1 \mathrm{mg}$ (40\%) and $0.35 \mathrm{mg}$ (59\%) demand doses than among patients treated with morphine $1 \mathrm{mg}(70 \%)$, with a significantly lower relative risk of $43 \%$ observed with the $0.1 \mathrm{mg}$ demand dose $(p<0.001)$. The incidence of vomiting across all the three demand doses of oliceridine, $0.1 \mathrm{mg}$ (20\%), $0.35 \mathrm{mg}$ (30\%), and $0.5 \mathrm{mg}$ (42\%), was lower than those reported with morphine $1 \mathrm{mg}$ (52\%); with a 41-61\% significantly lower relative risk observed with the $0.1 \mathrm{mg}$ and $0.5 \mathrm{mg}$ demand dose $(p<0.001)$ [20].

Although postoperative vomiting often accompanies postoperative nausea, physiologically, nausea, and vomiting are related, but distinct, physiological phenomena [21]. Nausea, by definition, is a subjective unpleasant sensation and poses an inherent limitation in measurement due to its subjectivity [22]. In contrast, vomiting is a demonstrable event, namely the forceful expulsion of stomach contents, where the intensity can be measured as the number of vomiting episodes [23]. From a patient and healthcare well-being perspective, nausea may decrease a patient's sense of wellbeing and increase anxiety; however, postoperative nausea alone poses limited health risks [5]. In contrast, postoperative vomiting can potentially result in significant health risks, including dehydration, electrolyte imbalances, and, in extreme cases, esophageal damage or aspiration $[5,24]$. Moreover, the cost associated with the treatment of a vomiting episode is significantly 
higher than that associated with nausea alone [24].

Based on these considerations, a conventional outcome in clinical trials of antiemetic medications or interventions for chemotherapy-induced vomiting has been identifying the proportion of patients who did not experience an episode of vomiting during treatment and who did not require the use of rescue antiemetics, referred to as "complete responders" [25-28]. In the data reported here, we use the endpoint of "complete GI response" to characterize the GI tolerability of the treatments studied in these two pivotal trials. This endpoint was evaluated for each treatment arm in both the phase 3 clinical trials. In addition, we also evaluated the complete GI response endpoint under equianalgesic conditions, where the analgesic effect was maintained at a constant level.

\section{METHODS}

As described in the previous publications of the pivotal trials, both studies were conducted in compliance with the protocol and regulatory requirements consistent with the International Council on Harmonization Good Clinical Practice Guidelines and the ethical principles of Declaration of Helsinki [18, 19]. A centralized institutional review board approved the trial protocols, and all patients provided written informed consent before any study procedures were performed.

Although similar in design, there were differences in the use of anesthetics (regional anesthesia with popliteal sciatic nerve block in the bunionectomy study and general anesthesia with the use of fentanyl and propofol in the abdominoplasty study), time from surgery to the first dose of study medication, different temporal courses of pain after discontinuation of anesthesia (within $9 \mathrm{~h}$ after discontinuation of regional anesthesia in the bunionectomy study, and within $4 \mathrm{~h}$ after surgery and at least 20 min after the last dose of fentanyl in the abdominoplasty study), different qualifying numerical rating scale (NRS) pain intensity scores, and the duration of the randomized treatment period ( $48 \mathrm{~h}$ for the bunionectomy study and $24 \mathrm{~h}$ for the abdominoplasty study) [18, 19] (Supplemental Fig. 1).

In both studies, patients aged 18-75 years, with a body mass index (BMI) $\leq 35 \mathrm{~kg} / \mathrm{m}^{2}$ and body weight $\geq 40 \mathrm{~kg}$, who underwent primary surgery of either bunionectomy (orthopedic surgery) or abdominoplasty (plastic surgery), and experienced moderate-to-severe pain as measured by the NRS [NRS $\geq 4$ for the bunionectomy study and NRS $\geq 5$ for the abdominoplasty study] were enrolled. Patients were randomized to receive intravenous (IV) demand dose regimens of a placebo, oliceridine $0.1 \mathrm{mg}$, oliceridine $0.35 \mathrm{mg}$, oliceridine $0.5 \mathrm{mg}$, or morphine $1 \mathrm{mg}$. For each regimen, a clinician administered a fixed IV loading dose (oliceridine $1.5 \mathrm{mg}$, morphine $4 \mathrm{mg}$, or volume-matched placebo) followed by demand doses administered via a patient-controlled analgesia (PCA) device and clinician-administered, blinded supplemental doses. PCA doses were allowed from $10 \mathrm{~min}$ after the loading dose and limited by a 6-min lockout interval. Blinded clinician-administered IV supplemental doses (oliceridine $0.75 \mathrm{mg}$ and morphine $2 \mathrm{mg}$ ) were permitted as often as hourly (PRN) (Supplemental Fig. 1). The dosing limit for all groups was three PCA syringes or six clinician-administered supplemental PRN doses within the first

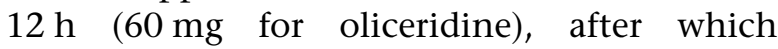
patients were discontinued and managed conventionally. In both trials, prophylactic antiemetics were not permitted preoperatively or during the randomized treatment period. However, patients were allowed to receive rescue antiemetic medication if they were actively vomiting, or at the patient's request if they reported moderate or severe nausea (graded on a four-category scale of none, mild, moderate, severe).

\section{Gastrointestinal Tolerability}

In the pivotal trials, the adverse events of nausea and vomiting that were spontaneously reported were assessed during the randomized treatment and 7-day follow-up period and coded using the Medical Dictionary for 
Regulatory Activities (MedDRA), version 19.0.26 [18, 19].

In this post hoc analysis, two outcomes were determined: (1) complete GI response, defined as the proportion of patients not experiencing the adverse event of vomiting and not using a rescue antiemetic, which was examined for each treatment arm by study and the pooled data from both studies and, (2) complete GI response endpoint observed between oliceridine and morphine when adjusted for equivalent levels of analgesic benefit. The method of adjustment for analgesic benefit is discussed further in the Statistical Analysis section that follows. For this latter analysis, all demand doses of oliceridine were pooled.

\section{Statistical Analysis}

Complete GI response was compared across assigned treatments using a logistic regression model with the main effects of treatment and baseline pain score. For the analysis assessing complete GI response when adjusted for equivalent analgesic levels, the complete GI response was adjusted for therapeutic effectiveness and compared by logistic regression, with the final model selected by backward elimination using the $p \leq 0.1$ criterion. Analgesic effect was quantified using the sum of pain intensity difference (SPID) appropriate to the acute treatment interval in each study, SPID-48 (orthopedic surgery-bunionectomy)/SPID-24 (plastic surgery-abdominoplasty), with pre-rescue SPID scores carried forward for $6 \mathrm{~h}$ for those patients who received protocol-specified rescue analgesic medication. Patients receiving placebo were excluded from this analysis. This model included the effects of treatment, baseline pain score, and SPID 48/24 (Table 1). This analysis was performed for each study separately and the pooled data for both studies combined. The full model for the individual studies (bunionectomy/abdominoplasty, respectively) included the complete GI response endpoint as the dependent variable with treatment (pooled oliceridine demand dose regimens of $0.1,0.35$, and $0.5 \mathrm{mg}$ as zero and morphine as one), baseline pain score, SPID
$48 / 24$ and the interaction terms of treatment by baseline pain score, treatment by SPID $48 / 24$, and baseline pain score by SPID $48 / 24$ as explanatory variables (Table 1 ). The full model for the pooled data from both studies utilized the same variables as for the individual studies, with the inclusion of study indicator (bunionectomy/abdominoplasty) and the explanatory variable (Table 1 ).

In the pooled data model, the interaction term of study ID and treatment was statistically significant $(p=0.0392)$. Upon further review of the study ID and treatment interaction terms, the benefit of oliceridine was consistent over morphine across both studies as the percentage of subjects who had complete GI response remained higher in the oliceridine group. The magnitude of the oliceridine complete GI response varied across the studies. Based on the significant relationship seen between study ID and treatment, it was noted that these studies should not be combined for the logistic analysis of complete GI response.

\section{RESULTS}

\section{Demographics}

Patient demographics were reported in the individual studies and previously published $[18,19]$. In both studies, the treatment regimens were balanced for age, race, and baseline characteristics. The mean age of patients was $45.1 \pm 13.5$ years in the orthopedic surgerybunionectomy study and $41.4 \pm 10.2$ years in the plastic surgery-abdominoplasty study, with mostly female patients $(84.8 \%$, bunionectomy study and 99.3\%, abdominoplasty study) and predominantly Caucasian (69.4\%, bunionectomy study, and $64.1 \%$, abdominoplasty study). The mean BMI was $26.5 \pm 4.3 \mathrm{~kg} / \mathrm{m}^{2}$ and $27.3 \pm 3.3 \mathrm{~kg} / \mathrm{m}^{2}$ in the bunionectomy and abdominoplasty studies, respectively $[18,19]$.

The majority of the study population enrolled in both the bunionectomy study and the abdominoplasty study mainly comprised of patients at increased risk of PONV, as defined by Apfel score criteria ( $\geq 3$ ) (Table 2). Furthermore, these data demonstrate that the representation 
Table 1 Logistic regression model to assess complete GI response between oliceridine and morphine

\begin{tabular}{|c|c|}
\hline Dependent variable & Explanatory variables \\
\hline \multicolumn{2}{|l|}{ Individual studies } \\
\hline \multirow{6}{*}{$\begin{array}{l}\text { Complete GI response (defined as no } \\
\text { vomiting and no use of rescue antiemetics) }\end{array}$} & Treatment ${ }^{*}$ \\
\hline & Baseline pain score \\
\hline & SPID 48 (bunionectomy)/24 (abdominoplasty) \\
\hline & The interaction terms of treatment by baseline pain score \\
\hline & Treatment by SPID $48 / 24$ \\
\hline & Baseline pain score by SPID $48 / 24$ \\
\hline \multicolumn{2}{|l|}{ Pooled studies } \\
\hline \multirow{10}{*}{$\begin{array}{l}\text { Complete GI response (defined as no } \\
\text { vomiting and no use of rescue antiemetics) }\end{array}$} & Study indicator \\
\hline & Treatment* \\
\hline & Baseline pain score \\
\hline & SPID 48 (bunionectomy)/24 (abdominoplasty) \\
\hline & Study indicator by treatment interaction \\
\hline & Study indicator by baseline pain score \\
\hline & Study indicator by SPID $48 / 24$, \\
\hline & Treatment by baseline pain score \\
\hline & Treatment by SPID $48 / 24$ \\
\hline & Baseline pain score by SPID $48 / 24$ \\
\hline
\end{tabular}

GI gastrointestinal, SPID sum of pain intensity difference

*Pooled oliceridine demand dose regimens of $0.1,0.35$, and $0.5 \mathrm{mg}$ as zero or morphine as one

of these risk strata was balanced across the treatment groups (Table 2).

\section{Gastrointestinal Tolerability}

The predominant rescue antiemetic used in both trials, was the 5-HT3 antagonist, ondansetron (Table 3 ).

\section{Complete GI Response (Post Hoc Analysis)}

The proportion of patients reaching the endpoint of complete GI response defined as not experiencing the adverse event of vomiting and not using a rescue antiemetic for each study by treatment arm is shown in Fig. 1. In the orthopedic surgery-bunionectomy study, a significantly greater proportion of patients in the placebo $(87.2 \%)$ and all oliceridine treatment regimens (0.1 mg: $76.3 \%, 0.35 \mathrm{mg}: 53.2 \%$ and $0.5 \mathrm{mg}$ : 49.4\%) achieved complete GI response compared to those patients allocated to morphine (32.9\%; $p<0.05$ vs. morphine) (Fig. 1a). In the plastic surgery-abdominoplasty study, complete GI response was achieved in a significantly greater proportion of patients only in the placebo $(66.3 \%)$ and oliceridine $0.1 \mathrm{mg}$ demand dose regimen (59.7 vs. $28.8 \%$ with morphine, $p \leq 0.0001$ ) (Fig. 1b). The proportion of patients achieving complete GI response with the oliceridine $0.35 \mathrm{mg}$ and $0.5 \mathrm{mg}$ demand dose were 39.2 and $29.9 \%$, respectively (Fig. 1b). 
Table 2 Apfel score by treatment in the phase 3 randomized clinical studies

\begin{tabular}{|c|c|c|c|c|c|}
\hline \multirow{2}{*}{$\begin{array}{l}\text { Apfel score } \\
n(\%)\end{array}$} & \multirow[t]{2}{*}{ Placebo } & \multicolumn{3}{|c|}{ Oliceridine demand dose } & \multirow{2}{*}{$\begin{array}{l}\text { Morphine } \\
1 \mathrm{mg}\end{array}$} \\
\hline & & $0.1 \mathrm{mg}$ & $0.35 \mathrm{mg}$ & $0.5 \mathrm{mg}$ & \\
\hline \multicolumn{6}{|c|}{ Hard tissue (orthopedic surgery-bunionectomy study) } \\
\hline $\mathbf{N}$ & 79 & 76 & 79 & 79 & 76 \\
\hline 0 & 0 & 0 & 0 & 0 & 0 \\
\hline 1 & $1(1.3)$ & $3(3.9)$ & $2(2.5)$ & $5(6.3)$ & 0 \\
\hline 2 & $14(17.7)$ & $14(18.4)$ & $20(25.3)$ & $14(17.7)$ & $21(27.6)$ \\
\hline 3 & $54(68.4)$ & $52(68.4)$ & $51(64.6)$ & $53(67.1)$ & $46(60.5)$ \\
\hline 4 & $10(12.7)$ & $7(9.2)$ & $6(7.6)$ & $7(8.9)$ & $9(11.8)$ \\
\hline \multicolumn{6}{|c|}{ Soft tissue (plastic surgery-abdominoplasty study) } \\
\hline $\mathbf{N}$ & 83 & 77 & 79 & 80 & 82 \\
\hline 0 & 0 & 0 & 0 & 0 & 0 \\
\hline 1 & 0 & 0 & 0 & 0 & 0 \\
\hline 2 & $3(3.6)$ & $5(6.5)$ & $6(7.6)$ & $7(8.8)$ & $6(7.3)$ \\
\hline 3 & $70(84.3)$ & $63(81.8)$ & $65(82.3)$ & $67(83.8)$ & $67(81.7)$ \\
\hline 4 & $10(12.0)$ & $9(11.7)$ & $8(10.1)$ & $6(7.5)$ & $9(11.0)$ \\
\hline \multicolumn{6}{|l|}{ Pooled studies } \\
\hline $\mathbf{N}$ & 162 & 153 & 158 & 159 & 158 \\
\hline 0 & 0 & 0 & 0 & 0 & 0 \\
\hline 1 & $1(0.6)$ & $3(2.0)$ & $2(1.3)$ & $5(3.1)$ & 0 \\
\hline 2 & $17(10.5)$ & $19(12.4)$ & $26(16.5)$ & $21(13.2)$ & $27(17.1)$ \\
\hline 3 & $124(76.5)$ & $115(73.4)$ & $116(73.4)$ & $120(75.5)$ & $113(71.5)$ \\
\hline 4 & $20(12.3)$ & $16(10.5)$ & $14(8.9)$ & $13(8.2)$ & $18(11.4)$ \\
\hline
\end{tabular}

Using a Cochran-Mantel-Haenszel raw mean score test to compare distribution across treatments-for hard tissue study, $p=0.584$; soft tissue study, $p=0.663$; pooled data, $p=0.307$. Apfel score assesses a patient's risk for postoperative nausea and vomiting based on known risk factors. Total score ranges from 0 to 4, with higher score indicating greater risk, and is the sum of positive responses to the following questions: is the patient female; does the patient have a history of postoperative nausea, vomiting, or motion sickness; is the patient a non-smoker; and does the patient have postoperative opioid use. In this study, all patients were considered as having postoperative opioid use

In the pooled data from both studies, a statistically significantly greater proportion of patients in the placebo regimen (76.4\%) and patients in two of the oliceridine treatment regimens, $0.1 \mathrm{mg}(68.0 \%)$ and $0.35 \mathrm{mg}(46.2 \%)$ achieved complete GI response compared to morphine $(30.8 \%, p \leq 0.005$ vs. morphine) (Fig. 2).

\section{Complete GI Response after Adjusting for Equivalent Levels for Analgesia with Oliceridine and Morphine}

After adjustment for analgesic effect, the odds ratio to experience complete GI response with oliceridine (combined demand doses) vs. morphine was 3.14 (95\% CI: 1.78, 5.56; $p<0.0001)$ 
Table 3 Rescue antiemetic medications by treatment groups utilized in the pivotal trials

\begin{tabular}{|c|c|c|c|c|c|}
\hline \multirow[t]{2}{*}{$n(\%)$} & \multirow[t]{2}{*}{ Placebo } & \multicolumn{3}{|c|}{ Oliceridine demand dose } & \multirow{2}{*}{$\begin{array}{l}\text { Morphine } \\
1 \mathrm{mg}\end{array}$} \\
\hline & & $0.1 \mathrm{mg}$ & $0.35 \mathrm{mg}$ & $0.5 \mathrm{mg}$ & \\
\hline \multicolumn{6}{|c|}{ Hard tissue (orthopedic surgery-bunionectomy study) } \\
\hline $\mathbf{N}$ & 79 & 76 & 79 & 79 & 76 \\
\hline Patients with at least one antiemetic & $9(11.4)$ & $14(18.4)$ & $28(35.4)$ & $34(43.0)$ & $46(60.5)$ \\
\hline Ondansetron & $7(8.9)$ & $14(18.4)$ & $28(35.4)$ & $34(43.0)$ & $46(60.5)$ \\
\hline Other antiemetics & $2(2.5)$ & 0 & $1(1.3)$ & 0 & 0 \\
\hline \multicolumn{6}{|c|}{ Soft tissue (plastic surgery-abdominoplasty study) } \\
\hline $\mathbf{N}$ & 83 & 77 & 79 & 80 & 82 \\
\hline Patients with at least one antiemetic & $24(28.9)$ & $26(33.8)$ & $44(55.7)$ & $48(60.0)$ & $53(64.6)$ \\
\hline Ondansetron & $24(28.9)$ & $25(32.5)$ & $44(55.7)$ & $48(60.0)$ & $53(64.6)$ \\
\hline Other antiemetics & $2(2.4)$ & $2(2.6)$ & 0 & $1(1.3)$ & $2(2.4)$ \\
\hline
\end{tabular}

Patients were counted once within each drug class and within each treatment group

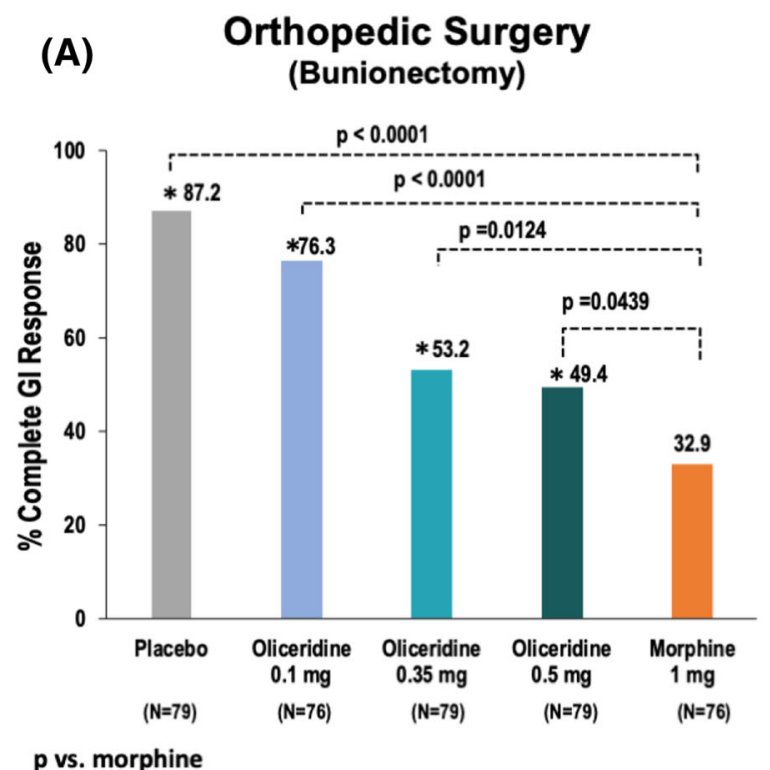

Fig. 1 Proportion of patients with complete GI response* by treatment in the two pivotal studies. ${ }^{*}$ Complete response defined as proportion of patients not experiencing adverse event of vomiting and not requiring use of

in the orthopedic surgery-bunionectomy study and 1.92 (95\% CI: $1.09,3.36 ; p=0.024)$ in the plastic surgery-abdominoplasty study. Across

\section{(B) Plastic Surgery \\ (Abdominoplasty)}

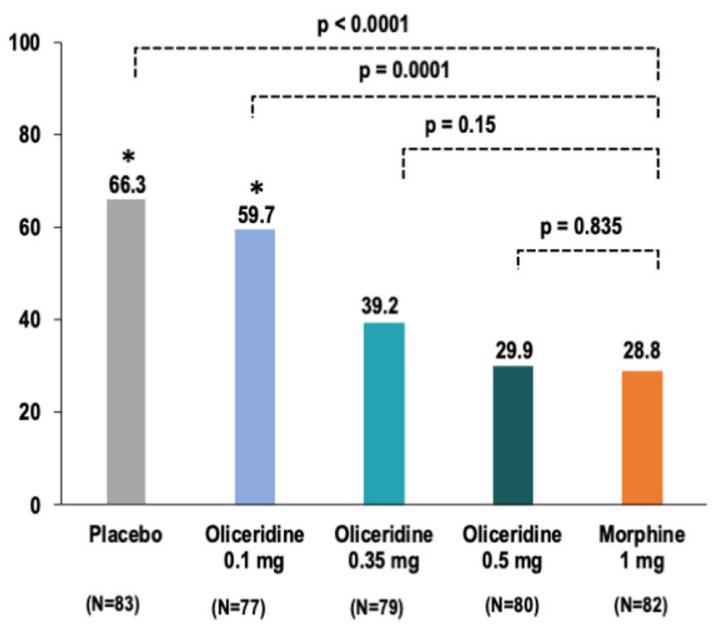

rescue antiemetics. Using a logistic regression modeling for complete response with treatment effect and baseline pain score, odds ratio and statistical significance vs. morphine were determined

both studies, the proportion of patients with a complete GI response remained higher in the oliceridine group vs. morphine (Fig. 3). 


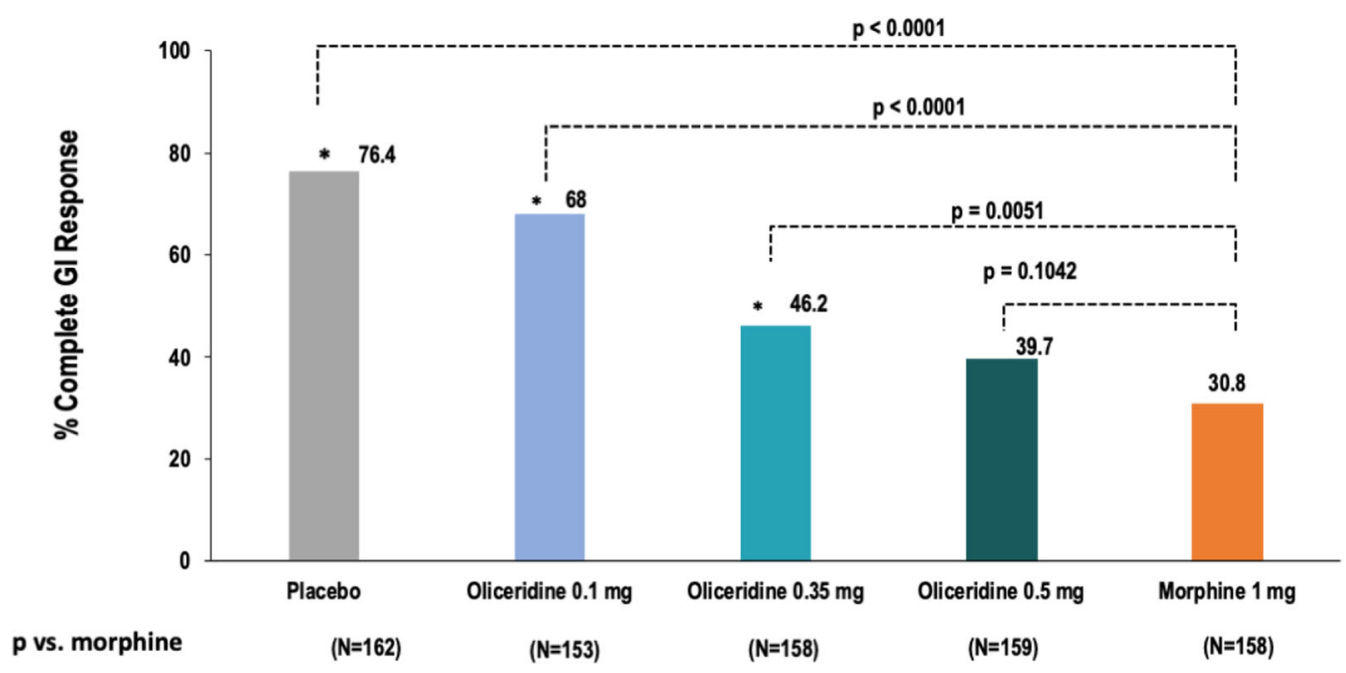

Fig. 2 Proportion of patients with complete GI response by treatment* in the pooled data set (combining the two pivotal trials). ${ }^{*}$ Complete response defined as proportion of patients not experiencing adverse event of vomiting and not requiring use of rescue antiemetics. Using a logistic regression modeling for complete response with treatment effect and baseline pain score, odds ratio and statistical significance vs. morphine were determined

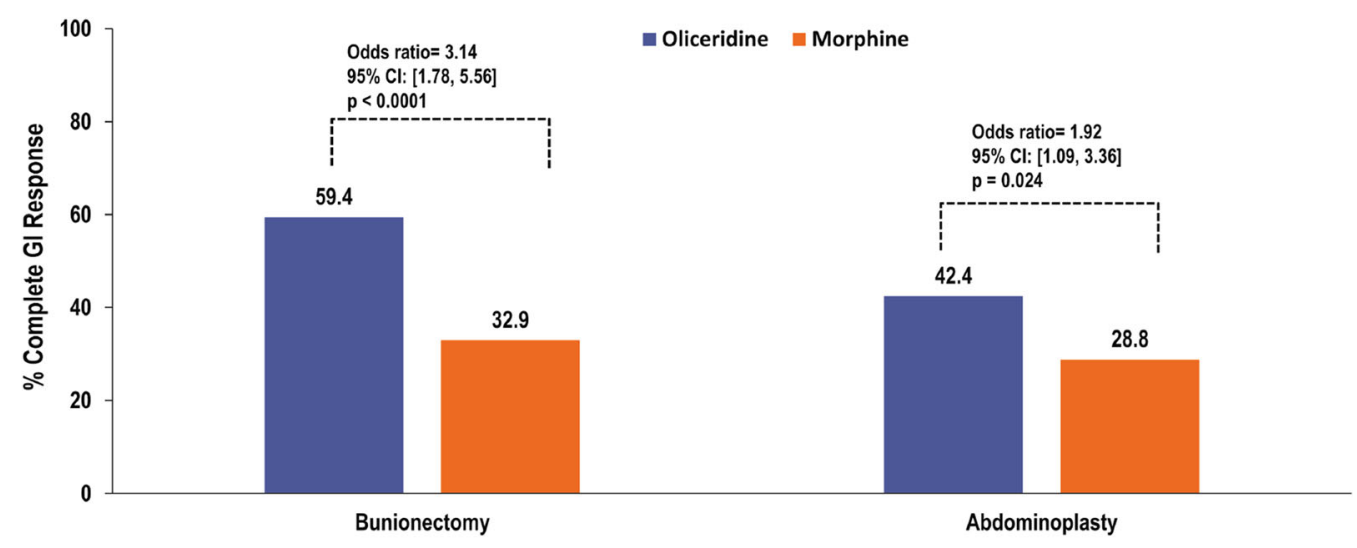

Fig. 3 Proportion of patients with complete GI response after adjusting for equivalent levels for analgesia with oliceridine and morphine in both pivotal studies. Data shown for oliceridine are pooled for all three doses $(0.1,0.35$, and $0.5 \mathrm{mg})$

\section{DISCUSSION}

The findings from this exploratory analysis demonstrate that oliceridine has a favorable advantage compared to morphine related to the safety endpoint of "complete GI response," defined as no vomiting and no use of rescue antiemetic medication. The findings persisted when controlled for the level of analgesia, with the odds of achieving complete GI response being 2-3 times higher with oliceridine than morphine. Notably, these findings were observed in a population of patients characterized as having an increased risk for PONV since the majority of patients had Apfel scores $\geq 3$ prior to enrollment. The Apfel score distribution was balanced across treatment groups. Although the protocol for both pivotal trials did not allow the use of prophylactic antiemetics, rescue antiemetics in patients were permitted in those who were actively vomiting, or at the patient's request if they reported moderate or 
severe nausea. Ondansetron was the most commonly used antiemetic across all treatment groups.

In this post hoc analysis, the clinical endpoint of complete GI response included the measure of no vomiting and no use of rescue antiemetic. While nausea is a subjective measure based on patient self-report and is not necessarily accompanied by vomiting [29], the occurrence of vomiting is clinically apparent and unambiguously quantifiable [23]. Rescue antiemetics were only allowed among patients experiencing an episode of vomiting or upon patient request if they experienced moderateto-severe nausea (based on categorical scale). Utilization of rescue antiemetics in patients experiencing nausea can prevent future vomiting episodes. Thus, including the measure of "no use of rescue antiemetics" in the clinical endpoint of complete GI response provides a more stringent circumstance for the measure of GI safety (vomiting) and provides the ability to discriminate the relative difference in this outcome between oliceridine and morphine.

Use of opioids to address postoperative pain is a major risk factor for the emergence of PONV $[8,30]$; however, the relative emetic potencies between various opioids are not well studied, and the few studies that compared opioids have reported no differences in the incidence of PONV [30, 31]. Thus, our findings that oliceridine exhibits improved GI tolerability compared to morphine is especially notable.

In clinical practice, opioids are usually not administered as the only analgesic; rather, they are typically utilized in an operationally defined regimen of multimodal analgesia [32]. Indeed, in the well-validated Apfel score used to predict the risk of PONV, the use of postoperative opioids is included as one of the variables [7]. The pivotal studies analyzed here did not use oliceridine or morphine as a part of multimodal analgesia; however, the bunionectomy trial used regional anesthesia with a popliteal sciatic nerve blockade and the abdominoplasty trial was performed under general anesthesia with endotracheal intubation using fentanyl and propofol. Our findings indicate that in the abdominoplasty study, complete GI response was significantly higher only with the oliceridine $0.1 \mathrm{mg}$ demand dose, and the responses observed with the 0.35 - and $0.5-\mathrm{mg}$ demand doses were not significantly different than those observed with morphine. The difference in the anesthesia regimen, in addition to the type of surgical procedure studied, could have contributed to the varied findings in the two studies. Indeed, studies have reported a lower incidence of PONV with regional anesthesia compared to general anesthesia $[4,33]$.

Although nausea and vomiting are adverse events of opioids, adequate pain control can also relieve PONV. Indeed, postoperative pain, especially of pelvic or visceral origin, is reported to lead to a higher incidence of postoperative nausea and vomiting [34]. In our analysis, after maintaining the analgesic effect at a constant level for both the oliceridine and morphine treatment groups, the odds of achieving complete GI response were three times higher with oliceridine than with morphine in the bunionectomy study and twice as high with oliceridine compared to morphine in the abdominoplasty study. Although the magnitude of the effect was lower in the abdominoplasty study, both studies showed a consistent positive benefit with oliceridine.

One of the limitations of this analysis is that the findings were based on post-randomization events. Nevertheless, the studies included here did not allow prophylactic use of antiemetics and thus maximized the ability to detect any differences between oliceridine and morphine related to PONV. Furthermore, the inclusion of populations studied under both forms of anesthesia allowed for a broader perspective of the risk profile. These findings suggest that oliceridine has a clinically significant GI safety advantage compared to the reference dose regimen of morphine when analyzed under equianalgesic conditions. Future prospective studies are needed to confirm these findings.

\section{CONCLUSIONS}

In summary, findings from this exploratory analysis show that the incidence of postoperative vomiting and use of rescue antiemetics was significantly lower in patients receiving 
oliceridine than morphine, and these beneficial effects persisted when controlled for the analgesic effects, based on SPID scores. The findings suggest that oliceridine, a G-protein selective MOR agonist, may have improved GI tolerability compared to morphine, and provides an important new option for the clinical management of postoperative pain.

\section{ACKNOWLEDGEMENT}

Funding. The studies included here in the exploratory analyses (orthopedic surgerybunionectomy, APOLLO-1; NCT02815709) and plastic surgery-abdominoplasty, APOLLO-2; NCT02820324) were sponsored by Trevena, Inc., Chesterbrook, PA. The exploratory analysis described here was also funded by Trevena, Inc. The funding for the Journal's Rapid Service Fee was provided by the study sponsor, Trevena, Inc.

Editorial Assistance. The authors wish to thank Kanaka Sridharan, M.S., R.Ph., an employee at Trevena Inc., for editorial assistance and creation of the figures. This assistance was funded by Trevena Inc.

Authorship. All named authors meet the International Committee of Medical Journal Editors (ICMJE) criteria for authorship for this article, take responsibility for the integrity of the work as a whole, and have given their approval for this version to be published.

Authorship Contributions. Design for this analysis: Mark Demitrack, Michael Fossler; Statistical analysis: Michael Fossler and Cathy Michalsky; Interpretation of the data: Internal authors- Mark Demitrack, Linda Wase and Michael Fossler; External authors- Timothy Beard, Keith A Candiotti, Paul Rider, Ashraf Habib and Eugene Viscusi contributed to interpretation of the clinical implications of the findings. Timothy Beard, Ashraf Habib and Eugene Viscusi provided direction to the development of the manuscript. Keith Candiotti, Paul Rider, Mark A Demitrack, Linda
Wase reviewed the draft manuscript and edited for scientific content. The final manuscript submitted was approved by all authors.

Disclosures. Timothy L. Beard was an investigator for Trevena and currently serves as a scientific advisor for Trevena Inc. Ashraf S. Habib and Eugene R. Viscusi were investigators participating in the past in Trevena funded studies. Keith A. Candiotti and Paul Rider were investigators for Trevena and served as consultants. Linda Wase, Cathy Michalsky, Mark A. Demitrack, Michael J. Fossler, are full-time employees and stockholders of Trevena Inc.

Compliance with Ethics Guidelines. Both studies were conducted in compliance with the protocol and regulatory requirements consistent with the International Council on Harmonization Good Clinical Practice Guidelines and the ethical principles of Declaration of Helsinki [18, 19]. A centralized institutional review board approved the trial protocols, and all patients provided written informed consent before any study procedures were performed.

Data Availability. The data sets generated during and/or analyzed during the current study are part of the New Drug Application under review at the US FDA and are not publicly available.

Open Access. This article is licensed under a Creative Commons Attribution-NonCommercial 4.0 International License, which permits any non-commercial use, sharing, adaptation, distribution and reproduction in any medium or format, as long as you give appropriate credit to the original author(s) and the source, provide a link to the Creative Commons licence, and indicate if changes were made. The images or other third party material in this article are included in the article's Creative Commons licence, unless indicated otherwise in a credit line to the material. If material is not included in the article's Creative Commons licence and your intended use is not permitted by statutory regulation or exceeds the permitted use, you will need to obtain permission directly from the copyright holder. To view a copy of this licence, 
visit http://creativecommons.org/licenses/bync/4.0/.

\section{REFERENCES}

1. Gan TJ, Belani KG, Bergese S, Chung F, Diemunsch $\mathrm{P}$, Habib AS, et al. Fourth consensus guidelines for the management of postoperative nausea and vomiting. Anesth Analg. 2020;131:411-48.

2. Sizemore DC, Grose BW. Postoperative Nausea. In: StatPearls. Treasure Island: StatPearls Publishing LLC; 2020.

3. Habib AS, Chen YT, Taguchi A, Hu XH, Gan TJ. Postoperative nausea and vomiting following inpatient surgeries in a teaching hospital: a retrospective database analysis. Curr Med Res Opin. 2006;22:1093-9.

4. Shaikh SI, Nagarekha D, Hegade G, Marutheesh M. Postoperative nausea and vomiting: a simple yet complex problem. Anesth Essays Res. 2016;10: 388-96.

5. Phillips C, Brookes CD, Rich J, Arbon J, Turvey TA. Postoperative nausea and vomiting following orthognathic surgery. Int J Oral Maxillofac Surg. 2015;44:745-51.

6. Oderda GM, Senagore AJ, Morland K, Iqbal SU, Kugel M, Liu S, et al. Opioid-related respiratory and gastrointestinal adverse events in patients with acute postoperative pain: prevalence, predictors, and burden. J Pain Palliat Care Pharmacother. 2019;33:82-97.

7. Apfel CC, Läärä E, Koivuranta M, Greim CA, Roewer N. A simplified risk score for predicting postoperative nausea and vomiting: conclusions from crossvalidations between two centers. Anesthesiology. 1999;91:693-700.

8. Roberts GW, Bekker TB, Carlsen $\mathrm{HH}$, Moffatt $\mathrm{CH}$, Slattery PJ, McClure AF. Postoperative nausea and vomiting are strongly influenced by postoperative opioid use in a dose-related manner. Anesth Analg. 2005;101:1343-8.

9. Smith HS, Smith JM, Seidner P. Opioid-induced nausea and vomiting. Ann Palliat Med. 2012;1: 121-9.

10. Coluzzi F, Rocco A, Mandatori I, Mattia C. Nonanalgesic effects of opioids: opioid-induced nausea and vomiting: mechanisms and strategies for their limitation. Curr Pharm Res. 2012;18:6043-52.
11. Rankovic Z, Brust TF, Bohn LM. Biased agonism: an emerging paradigm in GPCR drug discovery. Bioorg Med Chem Lett. 2016;26:241-50.

12. Raehal KM, Walker JK, Bohn LM. 'Morphine side effects in beta-arrestin 2 knockout mice. J Pharmacol Exp Ther. 2005;314:1195-201.

13. Bohn LM, Lefkowitz RJ, Gainetdinov RR, Peppel K, Caron MG, Lin FT. Enhanced morphine analgesia in mice lacking beta-arrestin 2. Science. 1999;286: 2495-8.

14. Raehal KM, Schmid CL, Groer CE, Bohn LM. Functional selectivity at the mu-opioid receptor: implications for understanding opioid analgesia and tolerance. Pharmacol Rev. 2011;63:1001-19.

15. Schmid CL, Kennedy NM, Ross NC, Lovell KM, Yue $\mathrm{Z}$, Morgenweck J, et al. Bias factor and therapeutic window correlate to predict safer opioid analgesics. Cell. 2017;171(1165-75):e13.

16. Chen XT, Pitis P, Liu G, Yuan C, Gotchev D, Cowan $\mathrm{CL}$, et al. Structure-activity relationships and discovery of a $\mathrm{G}$ protein biased mu opioid receptor ligand, [(3-methoxythiophen-2-yl)methyl](\{2-[(9R)9-(pyridin-2-yl)-6-oxaspiro-[4.5]decan- 9-yl]ethy1\})amine (TRV130), for the treatment of acute severe pain. J Med Chem. 2013;56:8019-31.

17. DeWire SM, Yamashita DS, Rominger DH, Liu G, Cowan CL, Graczyk TM, et al. A G protein-biased ligand at the mu-opioid receptor is potently analgesic with reduced gastrointestinal and respiratory dysfunction compared with morphine. J Pharmacol Exp Ther. 2013;344:708-17.

18. Singla NK, Skobieranda F, Soergel DG, Salamea M, Burt DA, Demitrack MA, et al. APOLLO-2: a randomized, placebo and active-controlled phase iii study investigating oliceridine (TRV130), a G protein-biased ligand at the mu-opioid receptor, for management of moderate to severe acute pain following abdominoplasty. Pain Pract. 2019;19: 715-31.

19. Viscusi ER, Skobieranda F, Soergel DG, Cook E, Burt DA, Singla N. APOLLO-1: a randomized placebo and active-controlled phase III study investigating oliceridine (TRV130), a G protein-biased ligand at the micro-opioid receptor, for management of moderate-to-severe acute pain following bunionectomy. J Pain Res. 2019;12:927-43.

20. Gan TJ, Wase L. Oliceridine, a G protein-selective ligand at the $\mu$-opioid receptor, for the management of moderate to severe acute pain. Drugs Today (Barc). 2020;56:269-86.

21. Joy Lin YM, Hsu CD, Hsieh HY, Tseng CC, Sun HS. Sequence variants of the HTR3A gene contribute to 
the genetic prediction of postoperative nausea in Taiwan. J Hum Genet. 2014;59:655-60.

22. Balaban CD, Yates BJ. What is nausea? A historical analysis of changing views. Auton Neurosci. 2017;202:5-17.

23. Graumlich JF, Belknap SM, Bullard SA, Storm GA, Brunsman KS, Howerton JA. Pharmaceutical care of postoperative nausea and vomiting: balanced scorecard for outcomes. Pharmacotherapy. 2000;20: 1365-74.

24. Hill RP, Lubarsky DA, Phillips-Bute B, Fortney JT, Creed MR, Glass PS, et al. Cost-effectiveness of prophylactic antiemetic therapy with ondansetron, droperidol, or placebo. Anesthesiology. 2000;92: 958-67.

25. Murakami C, Kakuta N, Kume K, Sakai Y, Kasai A, Oyama T, et al. A comparison of fosaprepitant and ondansetron for preventing postoperative nausea and vomiting in moderate to high risk patients: a retrospective database analysis. Biomed Res Int. 2017;570:3528.

26. Kranke P, Thompson JP, Dalby PL, Eberhart LH, Novikova E, Johnson BM, et al. Comparison of vestipitant with ondansetron for the treatment of breakthrough postoperative nausea and vomiting after failed prophylaxis with ondansetron. $\mathrm{Br} \mathrm{J}$ Anaesth. 2015;114:423-9.

27. Kang JH, Kwon JH, Lee YG, Park KU, An HJ, Sohn J, et al. Ramosetron versus palonosetron in combination with aprepitant and dexamethasone for the control of highly-emetogenic chemotherapy-induced nausea and vomiting. Cancer Res Treat. 2020;2020(52):907-16.

28. Oo TH, Hesketh PJ. 'Drug insight: new antiemetics in the management of chemotherapy-induced nausea and vomiting. Nat Clin Pract Oncol. 2005;2: 196-201.

29. Lu D, Wang Y, Zhao T, Liu B, Ye L, Zhao L, et al. Successful implementation of an enhanced recovery after surgery (ERAS) protocol reduces nausea and vomiting after infratentorial craniotomy for tumour resection: a randomized controlled trial. BMC Neurol. 2020;20:150.

30. Habib AS, Muir HA, Schultz JR, Olufolabi A, White WD, Gan TJ. Postoperative nausea and vomiting following the use of fentanyl or remifentanil in ambulatory gynecologic laparoscopic surgery: a prospective randomized trial. Ambul Surg. 2007;2007(13):1.

31. Shanthanna H, Paul J, Lovrics P, Vanniyasingam T, Devereaux PJ, Bhandari M, et al. Satisfactory analgesia with minimal emesis in day surgeries: a randomised controlled trial of morphine versus hydromorphone. Br J Anaesth. 2019;122:e107-13.

32. Chou R, Gordon DB, de Leon-Casasola OA, Rosenberg JM, Bickler S, Brennan T, et al. Management of postoperative pain: a clinical practice guideline from the American Pain Society, the American Society of Regional Anesthesia and Pain Medicine, and the American Society of Anesthesiologists Committee on Regional Anesthesia, Executive Committee, and Administrative Council. J Pain. 2016;17:131-57.

33. Borgeat A, Ekatodramis G, Schenker CA. Postoperative nausea and vomiting in regional anesthesia: a review. Anesthesiology. 2003;98:530-47.

34. Chatterjee S, Rudra A, Sengupta S. Current concepts in the management of postoperative nausea and vomiting. Anesthesiol Res Pract. 2011;2011:748031. 